\title{
DE LA DIGNIDAD EN LA DECLARACIÓN UNIVERSAL DE LOS DERECHOS HUMANOS DE 1948
}

\author{
Georges Navet ${ }^{1}$ \\ Universidad de París 8 \\ georges@orange.fr
}

\begin{abstract}
RESUMEN / ABSTRACT
La dignidad, referida a la persona humana, no aparece en la Declaración de los Derechos del Hombre y del Ciudadano de 1789. Solo apareció en ese tiempo en los escritos de Kant sobre moral. Sin embargo, la dignidad aparece en la Declaración Universal de los Derechos Humanos, que se presenta como un texto legal. Este artículo analiza las dificultades -su significación histórica de transferir esta noción moral a la ley. La Declaración de 1948 intentaba ser una respuesta a los horrendos sucesos ocurridos entre 1932-1945, durante los cuales se violó toda dignidad humana. Solo podía hacerlo apelando a la fe que la gente pudiera tener en la dignidad, sin ser capaz de procurar explícitamente referencia a Kant y su reino de los fines. La moralidad de Kant procura su fundamento y orientación a la ley, pero la ley introduce una coerción que solo le obliga a uno a conducirse "como si" uno actuara como un agente moral. Todo el problema radica en el "como si", con el cual la coerción y el acuerdo formal con la ley reemplazan de hecho una fe que quizá precisamente los sucesos del período 1932-1945 echaron por tierra.
\end{abstract}

PALABRAS ClAVE: derecho, moral, historia, “como-si”, juridización.

\section{ABout DIGNITY IN the UNIVERSAL DECLARATION OF HUMAN RIGHTS OF 1948}

Dignity as related to the human person does not appear in the 1789 Declaration of the rights of the man and of the citizen. It only appeared at the time in Kant's writings on morality. Dignity, however, appears in the 1948 Universal Declaration of human rights, which is presented as a legal text. The article analyzes the difficulties -and their historical significance- of transferring this moral notion to law. The 1948 Declaration was intended to be a response to the grim events that took place between 1932 and 1945 , during which all human dignity was violated. It can only do so by claiming the faith that people would have in dignity, without being able to afford to explicitly refer to Kant and his kingdom of ends. Kantss morality gives its foundation and orientation to the law, but the law introduces a constraint that only obliges one to behave as if one behaved as a moral agent. The whole problem is in the "as if", with which constraint and formal compliance with the law actually replace a faith that perhaps precisely the events of the period 1932-1945 have thrown down.

Keywords: Right, moral, history, “as if”, juritization.

Traducción del francés realizada por Carlos Contreras Guala y Britt Marie Benítez. 
$\overline{\mathrm{RA}}$ La dignidad es, en principio, un eminente cargo político, religioso o social (la dignidad real, la dignidad episcopal). Se dirá de un individuo que es digno de ese cargo si su manera de ser, de conducirse, de comportarse, lo pone a la altura de aquello que exige el cargo (ya sea que lo ejerza o no); la dignidad del individuo se mide entonces con las exigencias inherentes a un puesto (más o menos eminente) en una jerarquía que define ella misma sus propios criterios y que espera de sus "dignatarios" que se ajusten a ellos. El cargo confiere la dignidad y, sin embargo, puede ocurrir que desde el punto de vista de la jerarquía misma, un individuo revestido del cargo resulte indigno de él. Hay que distinguir este género de indignidad de otro que remite a lo más bajo de la escala, a aquellos que, cualquiera sea su comportamiento, nunca serán, nunca podrán ser dignos de esos cargos.

$\mathrm{Al}$ establecer que "todos los ciudadanos (puesto que iguales ante la ley) son igualmente admisibles a todas las dignidades, puestos y empleos públicos, según su capacidad, y sin otra distinción que la de sus virtudes y talentos", el artículo 6 de la Declaración de los Derechos del Hombre y del Ciudadano de 1789 pretende borrar incluso la posibilidad de ese segundo género de indignidad. En cuanto al primer género, está implícitamente retraducido en términos de incapacidad y de insuficiencia de virtudes y de talentos. El sustantivo "dignidad" conserva su antiguo sentido objetivo y el de "jerarquía" no aparece o solo aparece a través del de "distinción", como si los redactores hubieran querido abolir lo sagrado (hieros) de toda jerarquía. Si la palabra "sagrado" está presente en el preámbulo, califica allí los "derechos naturales, inalienables" del hombre, y no se aplica a una "distinción" que solo está justificada de manera derivada: justificada, solo cuando está fundada sobre la "utilidad común” (artículo 1) que, a su vez, no podría ser concebida sin que sean incluidos y respetados los "derechos naturales", únicos en estar dotados del aura de lo sagrado.

Esos derechos son esencialmente dos: la libertad y la igualdad. La libertad es consustancial al individuo, la igualdad no podría serlo, puesto que no podría existir sino entre los individuos. Ciertamente, la libertad también es llevada a ejercerse entre los individuos; lo hace de dos modos: tomando por límite la libertad del otro (artículo 4) y expresándose a través de la palabra, lo escrito o la impresión ("la libre comunicación de los pensamientos y de las opiniones", artículo 11). De este modo, ella pertenece, en primer lugar, al individuo como su sine qua non. Concebida esta vez, no ya como un cargo exterior y objetivo, sino como consustancial al individuo humano, la dignidad no aparece en este texto.

Ella no aparece en esa época sino en textos que surgen en una situación totalmente distinta. Se trata, evidentemente, de los textos de Immanuel Kant que surgen de la filosofía moral, de la Fundamentación de la metafísica de las costumbres de 1785 a los Principios metafísicos de la doctrina de la virtud de 1797. Podemos decir que esta dignidad (por lo demás, estrechamente vinculada a la libertad) es consustancial al individuo, a condición de precisar: ella pertenece al hombre en tanto que éste es un ser razonable y no simplemente un ser sensible. Que sea un ser razonable significa que tiene la capacidad de escapar a las tendencias y a las inclinaciones (de la sensibilidad) y de actuar según la representación de una ley racional, lo que hace de él (y de otros seres razonables) un fin en sí. Resulta de ello la pertenencia de los seres razonables a 
un "reino de los fines", de donde resultan a su vez las famosas fórmulas: "en el reino de los fines todo tiene o un precio o una dignidad. En el lugar de lo que tiene un precio puede ser puesta otra cosa como equivalente; en cambio, lo que se halla por encima de todo precio, y por tanto no admite nada equivalente, tiene una dignidad (...) aquello que constituye la condición únicamente bajo la cual algo puede ser fin en sí mismo no tiene meramente un valor relativo, esto es, un precio, sino un valor interior, esto es, dignidad"2. La dignidad kantiana pretende escapar a todo orden jerárquico social o político (ella es igual en cada hombre, cualquiera sea su lugar en la sociedad), pero ella no deja de contener algo sagrado: "la ley moral es santa (inviolable)". El hombre es sin duda bastante poco santo, pero la humanidad en su persona debe, para él, ser santa. Se trata, como sabemos, de la autonomía, la ley moral y la dignidad, del "supremo destino del hombre".

Destaquemos que son textos que surgen de la filosofía moral. La persona kantiana pertenece a dos mundos, el mundo sensible y el mundo inteligible. El mundo inteligible es el del ser moral y de su libre albedrío (freie Willkür), de "su libertad interior, su dignidad humana, innata". El derecho, por oposición a la moral, no se dirige sino al albedrío (Willkür) que puede también actuar solo según motivos sensibles. Desde el exterior, es decir, desde un punto de vista sensible, solamente puedo juzgar si una acción es acorde a aquello que exigiría la ley moral, no puedo saber si ella es auténticamente moral, es decir, determinada según las exigencias de la mera ley de la razón. El derecho se contenta con el punto de vista sensible. Puesto que no ocurre sin una instancia de coacción, es capaz de obtener acciones conformes a la moral, mientras que estas acciones pueden ser impulsadas por motivos totalmente distintos a los morales -el miedo a la policía, por ejemplo. Podremos decir, jugando con las palabras, que la gente respeta la ley (moral o jurídica), pero en un sentido que ya no tiene nada que ver con el respeto que inspiran (deben o deberían inspirar) la ley moral y la dignidad humana. El derecho no podría coaccionar un libre albedrío que, por definición, se determina fuera de toda coacción y entra, haciendo eso, en una lógica que es la de la obligación interior. Dicho de otro modo, la dignidad tomada en un sentido kantiano permanece siendo una noción extrajurídica, de la que podemos sostener que imanta el derecho, pero permaneciéndole externo o exterior: lo que puede obtener el derecho es, a lo más, que los seres humanos se conduzcan como si respetaran la dignidad en sí mismos y en los otros. Para expresarlo en términos no kantianos: el derecho es incapaz de producir una adhesión interior que no podría provenir sino del libre albedrío de los sujetos, es decir, de aquello sobre lo que el derecho no podría tener influencia.

Ahora bien, en diciembre de 1948, la dignidad parece abandonar la moral por el derecho, apareciendo en el primer "Considerando" de la Declaración Universal de los Derechos Humanos: "Considerando que el reconocimiento de la dignidad inherente a todos los miembros de la familia humana y de sus derechos iguales e inalienables

2 Kant, I., Fundamentación de la metafisica de las costumbres, traducción de José Mardomingo, Barcelona: Ariel, 1999, p. 200-201. 
constituye el fundamento de la libertad, de la justicia y de la paz en el mundo...". El estatuto de tal texto lo vincula con el de la Declaración de 1789, al que, por lo demás, hace alusión más de una vez. Pero ¿cuál es, justamente, ese estatuto? Si nos referimos al criterio kantiano de la coacción, el texto posee un carácter jurídico, puesto que está firmado, en 1948, por cincuenta y ocho Estados que se comprometen ipso facto a aplicarlo y que disponen de tal poder. El texto tiende, sin embargo, a tomar, particularmente con el artículo 30 y último, un giro metajurídico: "Ninguna disposición de la presente Declaración puede ser interpretada como implicando para un Estado, un grupo o un individuo, un derecho cualquiera de entregarse a una actividad o cumplir un acto que apunte a la destrucción de los derechos y libertades que aquí están enunciadas": no hay derecho, derecho digno del nombre de derecho, que pueda ir en contra de los derechos enunciados, incluso y sobre todo si pretende, para serlo, autorizarse de alguna interpretación del texto que los enuncia. Se trata de decir al menos, si no exactamente, lo que es el derecho, en qué casos ya no hay derecho.

Se mantiene la presencia desde la partida del término "dignidad", que a la vez evoca irresistiblemente a Kant y remite en él, no obstante, menos al derecho que a la moral. La Declaración de 1948, más claramente que la de 1789, evoca los motivos de su propia elaboración: "Considerando que el desconocimiento y el desprecio a los derechos humanos han conducido a actos de barbarie que suscitan la cólera de la conciencia de la humanidad y que el advenimiento de un mundo donde los seres humanos serán libres de hablar y de creer, liberados del terror y la miseria, ha sido proclamado como la más alta aspiración del hombre" (Segundo Considerando). Lo que introduce necesariamente la pregunta: ¿no es el sentimiento (y más que el sentimiento: la constatación,la certeza) de que todos los derechos han sido ofendidos y, más allá de los derechos, lo que les aportaba una imantación y un horizonte, lo que conduce a emplazar la dignidad en primera línea? El Considerando que acabamos de citar se refiere al "advenimiento" de un mundo futuro ("serán libres de hablar y de creer") que se parece mucho al "reino de los fines"; el Quinto considerando precisa que se trata también de "favorecer el progreso social e instaurar mejores condiciones de vida en una libertad más amplia". La promesa de porvenir se vuelve a enrielar con un pasado que es el de la Declaración de 1789: la Declaración de 1948 es a este respecto una re-declaración, una repetición que se quiere más profunda y más amplia, más "efectiva" ("asegurar, a través de medidas progresivas de orden nacional e internacional, su reconocimiento y aplicación universales y efectivas").

El porvenir, el pasado y, entre los dos, un descarrilamiento, un desvío sin precedente, donde todo lo que era considerado inviolable ha sido violado, donde todo lo que era considerado sagrado ha sido pisoteado. ¿Cómo responder a tal desafío y a través de qué? El Quinto Considerando lo hace con una palabra un tanto inesperada en un texto que se quiere jurídico: "Considerando que en la Carta los pueblos de las Naciones Unidas han proclamado de nuevo su $f e$ en los derechos humanos fundamentales, en la dignidad y el valor de la persona humana". La fe, o lo que haya de ser añadido a la proclamación de los derechos para que lleguen a ser "efectivos".

La dignidad en Kant es un "fin en sí”, tiene un "valor intrínseco" que inspira el respeto por sí misma, sin añadido exterior. Tal concepción, hemos dicho, es extrajurídica 
en la medida en que se refiere a una libertad interior sobre la que el derecho no tiene influencia, pero que, a la inversa, le da su orientación o su horizonte. Es posible, entonces, interpretar la "fe" de 1948 como una apelación al "fin en sí", al efecto que produce sobre toda libertad interior por poco que le preste atención seriamente. Si concedemos que la Declaración de 1948 es un texto de derecho (aunque tiende a lo metajurídico y toma a menudo, volveremos sobre ello, una forma de programa político), entonces hay que decir que aquí el derecho se preocupa de lo que, propiamente hablando, está fuera de él y que, sin embargo, le da su sentido y su base. El texto puede constatar la presencia de ese exterior (en la Carta de las Naciones Unidas) o intentar mostrar las consecuencias nefastas de su borradura, pero no puede explicitarlo y mucho menos producirlo a través de la coacción. Su kantismo difuso en efecto no podría, sin incongruencia, superar el estadio de lo implícito. De golpe desaparece la diferencia kantiana entre lo sensible y lo inteligible, es decir, lo que confería a la dignidad, a la libertad interior, al respeto de la persona, una dimensión distinta y superior (sagrada o cuasi sagrada). Todo se orienta hacia lo sensible, o más precisamente hacia lo histórico, animado por una "aspiración" interna que sería la de la humanidad hacia más humanidad, una aspiración que se ha expresado una primera vez en el último cuarto del siglo XVIII. Restablecer, querer restablecer un movimiento supuestamente aún en expansión, ¿no era -ya sea por fervor ligado a la victoria y a la Liberación, ya sea por un sentimiento de urgencia o porque no se podía hacer nada mejor en el momento- descuidar o, más precisamente, pasar por alto una pregunta fundamental? Lo que tuvo lugar entre 1932 y 1945, ¿no conmueve profundamente la "libertad interior", sus capacidades de experimentar y de creer?

La borradura de la dimensión de lo inteligible priva a la dignidad del trasfondo que la volvía, al mismo tiempo, sagrada e indiscutible; he aquí que ella desciende a un nivel empírico, y el esfuerzo manifiesto de los redactores de la Declaración de 1948 por restituirle ese doble carácter choca sin cesar con el hecho de que ellos no pueden, a pesar de todos sus argumentos, exigir más que una adhesión subjetiva -es decir, una adhesión siempre susceptible de encontrarse con el escepticismo, con la indiferencia o con adhesiones a cualquier otra cosa. Pero ¿no es justamente sobre ese fondo empírico que su texto adquiere su aspecto más admirable, el de ser un texto de combate - de combate en nombre de la dignidad?

Un cierto número de juristas, ya sea que su argumentación esté preorientada políticamente o sea simplemente técnica, ponen en duda la pertinencia operatoria de la noción de "dignidad" en derecho: noción confusa, incapaz de proveer principios claros, que introduce afectos, pasiones, consideraciones morales o filosóficas allí donde no tienen lugar de ser. Podemos afirmar, sin forzar las cosas, que los redactores de 1948 introdujeron la dignidad en derecho, la emplazaron más bien anticipadamente, aunque esa anticipación no deja de tener repercusiones sobre su posterioridad. Su combate es así doble: anticipadamente, del lado socio-político, suscitar la mayor adhesión posible; posteriormente, del lado propiamente jurídico, dar al derecho cierta orientación. En cuanto a su noción de dignidad, no afirmaremos que es transparente, sino que adquiere su claridad precisamente porque ella es la apuesta de un combate en un contexto y en circunstancias muy definidas. 
Concedamos a sus detractores que la idea de dignidad toma un carácter confuso desde el momento en que intentamos delinear y trazar sus contornos. Existen al menos tres razones para esto. La primera es que la dignidad y su idea no nos llegan sino a través de las experiencias (las nuestras o las de otro) donde nosotros las sentimos, en primer lugar, de modo afectivo. La segunda es que el afecto es paradojalmente tanto más intenso en cuanto nos llega a través de un desvío negativo: la dignidad ultrajada, la dignidad herida, la dignidad negada, en el transcurso de experiencias donde lo pasivo (ser ultrajada, ser herida, ser negada) parece preceder a su sujeto (la dignidad), suscitarlo y revelarlo a sí mismo. La cosa es tan verdadera que la dignidad, tomada fuera de los momentos en que viene a reconquistarse, fuera de los momentos en que debió luchar para imponerse, arriesga rápidamente con degenerar en autosatisfacción o en suficiencia. La tercera es que las experiencias parecen escapar a una síntesis o a una inducción que establecería, de una vez por todas, lo que es "la" dignidad - quizá porque los dispositivos susceptibles de proveer ocasiones de ultrajarla son tan numerosos (y el porvenir nos reserva, sin duda, ocasiones inéditas) que es imposible clasificarlas y reagruparlas bajo el mismo título.

La dignidad es más bien reconocida que conocida y no se aclara o no adquiere un rostro sino en las luchas que son realizadas en su favor por aquellos que han hecho (sobre sí mismos o sobre otros) la penosa experiencia de su denegación. Que esas luchas socio-políticas sostengan reivindicaciones que pueden traducirse en términos jurídicos va de suyo; pero son también sus repercusiones, más bien que una evolución interna del derecho, quienes han llevado a la noción misma de dignidad a introducirse en ese dominio. Y allí, la traducción es más difícil, puesto que no es posible partir de una definición de la dignidad que delinearía todos sus contornos, sintetizaría todos los rostros y ofrecería una base de acuerdo, de una vez por todas, a partir de la cual el jurista podría razonar en términos de consecuencias.

La juridización, el llegar a ser norma jurídica de una idea hasta ese momento (es decir, en resumidas cuentas, hasta los años 1990) relegada al dominio de los grandes discursos vagos (comprendida la Declaración de 1948) que saludamos antes de pasar a las cosas serias, significa mucho en cuanto a la evolución de la sociedad. En el reino de los fines, el respeto de la dignidad no necesita de ningún derecho para imponerse, no necesita de la mediación de una instancia tercera y obligante. Que ese desvío sea sentido cada vez más como una necesidad prueba que nos sentimos lejos, muy lejos, de ese reino de los fines, y que las relaciones sociales van por sí mismas en un sentido del todo opuesto. Si eso que hemos dicho del desvío negativo que toma prestada la dignidad para manifestarse en su mayor virulencia tiene la menor verdad, entonces hay que decir que el llegar a ser norma (con sus dificultades internas) de la dignidad es más bien el signo de la proliferación efectiva de los actos de indignidad. En la mejor de las hipótesis, el derecho no puede obtener sino una cosa: que los humanos se comporten como si respetaran la dignidad. Kant presuponía la presencia en el corazón de los humanos (y por lo tanto de la sociedad) de un sentido que les permitía reconocer una conducta conforme a la moral y, por lo tanto, reconocer lo bien fundada de una ley jurídica que obliga a tal conducta: de este modo, daba una consistencia al como si jurídico. ¿Qué ocurre cuando tal consistencia se desmorona y el como si tiende a transformarse en la máscara falsa de una realidad completamente diferente? 